\title{
Sinais Divinos E Prodígios na Construção da Imagem de Augusto: Um Estudo a Partir de Suetônio
}

\author{
Carlos Eduardo da Costa Campos ${ }^{1}$
}

RESUMO

O papel sociopolítico da religião e dos rituais são elementos cruciais para o estudo das instituições romanas. Afinal, a esfera religiosa integra um complexo sistema epistemológico produzido pela elite romana e relacionado aos diversos segmentos sociais de Roma. Dessa forma, a partir dos discursos de Suetônio, analisaremos a construção da legitimidade de Augusto através dos sinais divinos e prodígios.

PALAVRAS-CHAVE

Prodígios; Senado; Suetônio; Otávio Augusto.

\footnotetext{
${ }^{1}$ Doutor e Mestre em História pelo Programa de Pós-Graduação em História da Universidade do Estado do Rio de Janeiro (UERJ). Professor Adjunto de Pré-História, História Antiga e Medieval da Faculdade de Ciências Humanas da Universidade Federal do Mato Grosso do Sul (FACH/UFMS) e docente do Programa de Mestrado Profissional em Ensino de História (PROFHISTÓRIA) da Universidade do Estadual de Mato Grosso do Sul (UEMS). Pesquisador do Museu de Arqueologia da UFMS; Coordenador do Grupo de Pesquisa no CNPQ - ATRIVM / UFMS; Coordenador da área de História (FACH) no Programa Institucional de Bolsa de Iniciação à Docência (PIBID). E-mail para contato: carlos.campos@ufms.br
} 
Mare Nostrum, ano 2021, v. 12, n. 1 .

\section{Introdução}

Grande parte das autoridades religiosas do Mundo Antigo combinava seus deveres sacerdotais com outras funções sociais, principalmente com as funções do campo político. Os principais magistrados romanos também poderiam assumir postos sacerdotais na dinâmica religiosa, o que significa dizer que o poder e a autoridade sacerdotal eram respeitados na ordem social e política de Roma. Diante disso, pretendemos analisar, a partir do biógrafo Suetônio, o papel dos prodígios e outros sinais divinos na construção da auctoritas de Otávio Augusto. Iniciaremos nosso estudo apontando o papel das instituições na vida religiosa romana para compreendermos suas relações com o discurso de Suetônio e as ações do Senado nesse contexto.

Os magistrados, que celebravam os grandes jogos para os deuses, que faziam sacrifícios e tomavam os auspícios, também assumiam funções sacerdotais nos colégios (Szemler, 1972, p. 6). Na realidade, sacerdotes e magistrados eram depositários de poderes de distintas naturezas: os primeiros pertenciam ao domínio do ius sacrum direito sagrado - e os últimos, ao ius publicum - direito de atuação na vida pública. Eles eram independentes, porém, a nosso ver, deviam convergir para a gestão eficaz da religião pública e da ordem social. As diferenças entre magistrados e sacerdotes também se traduziam no modo específico de recrutamento de seus integrantes, nas suas regras, privilégios e insígnias particulares. Apesar disso, ambos os grupos pareciam interagir entre si, afinal, muitos sacerdotes vinham de famílias que, ano após ano, disputavam e, muitas vezes, assumiam funções nas magistraturas.

Cabia às principais magistraturas de Roma o papel de mediação entre homens e deuses para o ordenamento cívico. Em particular, o magistrado presidia e garantia a aprovação divina de cada assembleia: durante a noite anterior, no lugar em que ela deveria ocorrer, o magistrado precisava "tomar os auspícios", ou seja, um sinal de que os deuses estivessem a favor dos procedimentos (Beard, 1990, p. 31-34). Havendo esse sinal, a assembleia acontecia. É claro que tal aprovação religiosa também poderia ser alvo de disputas e interesses particulares, podendo o magistrado ou sacerdote declarar um presságio contrário ao evento. No entanto, destacamos que, em princípio, o magistrado responsável detinha o papel institucional de zelar pela correta relação entre a atividade política e os desígnios divinos. Dessa forma, as fraudes e a corrupção religiosa deveriam ser evitadas, ao menos no plano ideal. 
Pode-se acrescentar que a magistratura e os colégios sacerdotais eram solidários e traduziam o princípio básico republicano, que consistia na colegialidade do poder romano. Ambas as instituições, no entanto, dependiam estritamente de uma terceira, o Senado, que funcionava como um órgão decisório supremo da República. Assim, os sacerdotes e os magistrados atuavam, em última instância, como conselheiros conhecedores da execução dos rituais somente por vontade do Senado. Além disso, a partir dos estudos de Beltrão da Rosa (2003, p. 20-42), Szemler (1971, p. 103-31) e José A. Delgado (2000, p. 28-30), percebemos que, devido às relações com o Senado, a historiografia estabeleceu diferenciações entre os colégios sacerdotais romanos. Sendo assim, podemos distinguir os colégios em: os quatro grandes colégios sacerdotais (pontífices, áugures, quindecênviro e epulões ${ }^{2}$ ) que eram consultados frequentemente pelos senadores; os fetiales e os arúspices, consultados ocasionalmente; e os sálios, os lupercos e os fratres arvales ${ }^{3}$, que nunca eram consultados.

Portanto, vemos que um dos papéis mais importantes do Senado era a tomada de decisões sobre os problemas que envolviam as relações entre homens e deuses, bem como o ordenamento social dos rituais romanos (Beard, 1990, 31-34). Como já vimos, o Senado não era a única instituição que dispunha dessas prerrogativas - pois havia também as assembleias, os magistrados e os grupos sacerdotais -, mas ele certamente se destacava na dinâmica religiosa de Roma junto aos quattuor amplissima collegia sacerdotum.

\footnotetext{
${ }^{2}$ Em De haruspicum responso, 14, Cícero argumenta que o zelo pelos sacra integrava as funções do colégio dos pontífices, o que leva a competências das esferas públicas e privadas que modernamente se situam na parte secular da sociedade. Assim, a partir de leituras sobre Cícero, vemos que os pontífices eram os responsáveis pelos rituais considerados como solenes romanos. Segundo J. A. North (2000) os áugures atuavam como "supervisores e conselheiros sobre os rituais e procedimentos concernentes aos auspícios" (p. 23). Individualmente, os áugures estavam capacitados para: emitir responsa, celebrar ritos diversos, conhecidos como auguria; celebrar, mediante solicitação expressa, as inaugurações de sacerdotes e templos; auxiliar os magistrados na tomada dos auspícios. Igualmente, tinham o direito de anunciar, com caráter vinculante, a presença de auspícios desfavoráveis, o que automaticamente interrompia um ato público. Os duo/decem/quindecimviri sacris faciundis tinham como suas competências: custodiar os Livros Sibilinos, que eram uma coleção de oráculos gregos contendo basicamente os procedimentos rituais, não profeciais; consultar tais livros (sempre por ordem do Senado), especialmente em ocasiões de prodígios ou desastres, além de comunicar ao Senado os recursos religiosos possíveis para sanar tal questão. Os tres/septemviri epulones tinham como suas competências a organização dos banquetes sagrados, que deveriam ser feitos aos deuses (epulae publicae), especialmente a Júpiter (epulum Iovis), celebrado nos idos (dia 13) de setembro e novembro (Lívio, Hist. Rom. 33.42; Cic. De Har. Resp. 10; Dião Cássio, Hist. Rom. 43.51).

${ }^{3}$ Segundo North (2000, p. 23-24), os fetiales eram os sacerdotes responsáveis pelos tratados envolvendo assuntos exteriores a Roma: declaração de guerra, trégua, rendição do inimigo etc. Os arúspices são sacerdotes de matriz etrusca, especialistas nas artes da adivinhação, no conhecimento dos prodígios dos deuses e na leitura das entranhas das vítimas sacrificiais. Já os lupercos eram sacerdotes que atuavam na festa da Lupercália, portando chicotes de pele de cabra e batendo nas pessoas enquanto elas corriam pelas ruas da Vrbs. Por fim, a função dos fatres arvales era preservar o culto da Dea Dia, realizado numa gruta fora de Roma.
} 
Também cabia ao Senado a introdução de novos cultos. Foi ele que ordenou e autorizou, em 205 AEC, que o culto da deusa frígia Cibele deveria ser trazido para Roma, a fim de assegurar a vitória no contexto desfavorável que Roma vivenciava na Segunda Guerra Púnica. Sobre o fato, Tito Lívio menciona que

Naquela época, um receio religioso emergiu de assalto entre os cidadãos, o que levou à consulta dos livros sibilinos, principalmente devido às frequentes chuvas de pedras [granizo]. No referido ano, o oráculo informou que, se algum inimigo estrangeiro viesse a invadir a Península Itálica, ele poderia ser expulso e derrotado se a Mãe do Ida fosse trazida do Pessinonte para Roma. Tal predição, descoberta pelos decênviros, impactou tanto os senadores quanto aos embaixadores encarregados de levar oferenda a Delfos. Estes também relataram que, em seus sacrifícios a Apolo Pítio, as entranhas se mostraram favoráveis e que o oráculo respondeu que uma vitória muito maior do que todos os espólios que estavam sendo oferecidos seria dada ao povo romano. [...] E assim, quanto mais cedo estivessem em posse da vitória, o oráculo se cumpriria. Eles então planejaram e discutiram o que deveria ser feito para o transporte da deusa para Roma. (Hist. Rom. 29.10, 4-8)

Tito Lívio argumenta que a notícia da transposição da mãe do Ida para Roma circulou por diversos locais como uma forma de apaziguar e animar as legiões romanas. Afinal, a religião se relacionava com os temores da guerra sob tutela dos decênviros e dos senadores (Hist. Rom. 29.11,1-5; 29.14, 5-14). Por outro lado, Lívio nos informa que o Senado poderia proscrever cultos "estrangeiros" na cidade de Roma. Por exemplo, em 186 AEC, o Senado tomou medidas restritivas (senatus consultum) contra o culto de Baco na Península Itálica (Hist. Rom. 39. 8-19). Também sabemos de medidas contra o culto de Ísis, em Roma, no ano de 50 AEC, período marcado pelo acirramento das animosidades com o Egito, em virtude das relações entre Júlio César e Cleópatra VII (Valério Máximo, Feitos e Ditos Memoráveis, 1. 3-4).

O Senado também tinha de lidar com os problemas que surgiam a partir da conspurcação dos rituais, a fim de restabelecer a ordem cósmica e social. Um exemplo disso foi o grave incidente, envolvendo Clódio Pulcro na cerimônia noturna da Bona Dea (Boa Deusa), que era exclusiva às mulheres. Cícero (Att. 1.13.3) comenta que, no ano de 61 AEC, um homem invadiu o ritual. Apesar de o autor de tamanha profanação não ter 
sido identificado, acreditava-se que foi Clódio Pulcro, visto que ele pretendia perder seu status de patrício para ter chances de concorrer ao cargo de tribuno, muito embora haja várias versões para a sua motivação. O Senado logo interveio, tomando, antes de tudo, a iniciativa de instruir as Virgens Vestais para que reconduzissem a cerimônia corretamente, bem como de notificar o colégio dos pontífices para que se investigasse o incidente. Assim, no caso de uma ruptura tão óbvia dos rituais, foi o Senado quem dirigiu e coordenou as respostas religiosas para a preservação da pax deorum.

Ao Senado também cabia - junto aos colégios sacerdotais - realizar outras atividades religiosas, como as acclamationes, que eram performances orais endereçadas às divindades, visando atraí-las para a execução de um ato religioso envolvendo rituais públicos (Rosa, 2010, p. 42-60). As acclamationes tinham função propiciatória e se conectavam a outras cerimônias, como a euocatio, na qual se convocavam as divindades inimigas a se aliarem ao lado romano em contextos de guerra. A euocatio foi empregada, por exemplo, na Guerra de Veios, em que a deusa etrusca Une foi entronizada como Juno Regina no Capitólio. Outra função das acclamationes revelava o seu aspecto testemunhal, ou seja, os deuses eram convidados para testemunhar em favor do celebrante, como pode ser visto nas ações dos feciais e nos tratados de guerras. Por fim, a terceira atividade se denominava instauratio, um ritual para refazer ou retomar uma parte da cerimônia que tenha sido conspurcada por falhas humanas (Rosa, 2010, p. 42-60; Scheid, 1981, p. 171177). Sendo assim, ao solicitar às Vestais a repetição correta dos rituais, o Senado pretendia fazer com que o colégio responsável pela cerimônia executasse a instauratio como um instrumento da religio ${ }^{4}$.

Claro que o Senado poderia e deveria tomar o conselho dos vários corpos sacerdotais, mas a decisão final, irremediavelmente, seria promulgada por ele (North, 2000, p. 24). Dessa forma, magistrados e Senado controlavam, na prática, tanto as formas de adoração quanto a consulta aos auspicia, assim como a interpretação e expiação dos prodígios (Santangelo, 2013, p. 5-14). No caso dos prodigia, era o colégio dos pontífices

\footnotetext{
4 Evidenciamos que os antigos romanos aplicavam dois termos distintos para expressarem o que compreendiam como religio. Assim, é possível verificarmos tanto a terminologia religare (conotação de ligar) quanto o termo relegere (que nos indica a função de controlar ou de zelo religioso). Destacamos que a primeira designação indica a religião como um elemento que vinculava as comunidades humanas ao plano do divino; já no segundo caso, a religião é a responsável pelo zelo da observância entre os homens e os deuses, na procura pela preservação da pax deorum (paz com os deuses). É possível inferir que a religio gerava um sentimento de obrigação, ou seja, um relacionamento pelo qual os humanos - tanto como agentes individuais e/ou como coletivos - estavam vinculados, no sentido do verbo religare, para adorar os deuses. Os cidadãos, enquanto agentes religiosos, eram responsáveis por manter o culto aos deuses (cultus). Então, podemos dizer que a religio englobava magistrados, senadores e sacerdotes para o ordenamento religioso.
} 
que detinha a responsabilidade da interpretação sobre determinados fenômenos da natureza, os quais eram considerados como incomuns.

Segundo Bruce MacBain (1982, p. 7-8) e Beltrão da Rosa (2006, p. 141), os prodígios formavam um conjunto significativo de eventos sagrados no imaginário social romano, os quais indicavam uma ruptura com a pax deorum, o que requeria certamente uma solução através de ritos expiatórios. Vale mencionar que os cônsules, no início de cada ano, eram responsáveis por informar ao Senado sobre os prodígios que foram detectados no ano que havia encerrado. É interessante demarcar a necessidade de interação entre magistrados, sacerdotes e senadores sobre a análise e possível ritual de expiação para um prodígio.

Muitos prodígios são mencionados em Tito Lívio (Hist. Rom. 5.10.1-2; 5.31.5;7.2.1-7) e em outros autores, dentre eles Dionísio de Halicarnasso, Valério Máximo e Dião Cássio. Em todos eles, verificamos a tomada de decisões do Senado, que atestava as prodigia publica, ou seja, os sinais referentes ao andamento social da Vrbs. Para MacBain (1982, p. 7-8), as evidências literárias permitem observar duas tendências da época quanto aos prodígios: uma que considera os relatórios dos prodígios como algo passível de manipulação e, portanto, submetido ao puro interesse político; outra que os via como uma histeria coletiva, às vezes até grave para ordem social, devido ao furor religioso que eles costumavam acarretar. Apesar dessas críticas, não podemos esvaziar ou invalidar o prodígio enquanto experiência religiosa coletiva importante para o povo romano ao longo dos séculos. Assim, o cotidiano religioso da grande população, somado aos interesses das elites, formam um conjunto de dados importante para a pesquisa histórica sobre Roma. Da mesma forma, os prodígios que eram relatados nas cidades nãoromanas da Península Itálica também deveriam ser interpretados, uma vez que se atrelavam às demandas sociais e serviam para identificar o estado de ânimo dos povos itálicos, particularmente em momentos de graves tensões da República.

Os prodígios, como muitos elementos da religião romana, estavam sob o controle dos segmentos dirigentes. Por estarem fortemente arraigados no cotidiano religioso e serem passíveis de manipulação, eles conferiam certas vantagens políticas para os senadores e mandatários romanos na condução da República e do Principado, como vemos na construção do poder de Augusto.

Suetônio nos dá uma noção do papel dos prodigia em sua construção biográfica euforizada de Augusto. Valendo-se dos indícios documentais, o biógrafo demonstra que o sucesso de Augusto em promover modificações político-religiosas em Roma está 
relacionado ao seu próprio nascimento. Afinal, muitos governantes legitimavam seu poder através de narrativas que envolviam acontecimentos divinizados em torno de suas origens. Nelas, é frequente o amplo uso de imagens, símbolos e modos de agir que possibilitam a construção - e reconstrução - idealizada de um personagem a serviço dos interesses do poder vigente. Tais narrativas, portanto, criam e asseguram ao biografado uma herança divina em sua trajetória política: “[...] por termos tocado nesses assuntos, não há por que calar os incidentes que lhe sobrevieram antes do nascimento, nesse mesmo dia ou mais tarde, pelos quais se poderia esperar ou perceber sua grandeza futura e sua contínua ventura." (Aug. 94) Sob essa ótica, o discurso mítico ${ }^{5}$ nos fornece uma trajetória para o sucesso de nosso personagem Augusto, transformando-o num mito político ${ }^{6}$ para Roma:

Há muito, tendo sido atingida uma parte do muro de Velitras, por um raio, foi predito que um dia um cidadão do lugar haveria de tomar o poder; confiando nesse augúrio, os veliternos lutaram desde essa ocasião e em seguida, com muita frequência e quase até sua destruição, contra o povo romano; mais tarde, finalmente se manifestou por indícios que aquele presságio profetizava o poder de Augusto. (Aug. 94)

Essas descrições revelam que cabia a Augusto a função de ordenador do caos social vivenciado em Roma no século I $\mathrm{AEC}^{7}$. Assim, entendemos o raio como um dos atributos do rei dos deuses romanos, Júpiter, que demarcaria em Velitras o local de nascimento do homem que seria capaz de organizar e governar "toda a Terra" segundo o

\footnotetext{
${ }^{5}$ Os grupos sociais criam um conjunto de discursos frente à sociedade com base em mitos que legitimem pessoas ou ações. Logo, os discursos míticos são produzidos no imaginário social como uma forma eficiente de controle da coletividade e também um meio de legitimação do poder dos indivíduos" (Baczko, 1984, p. 297).

${ }^{6}$ Raoul Girardet (1987) demarca que os mitos políticos são construções discursivas sobre as trajetórias políticas e sociais de indivíduos, em muitos casos, lhes conferindo vinculações com a esfera do sagrado. Quanto mais um mito político ganha aceitação na sociedade, "[...] mais ele se estende por um largo espaço cronológico e se prolonga na memória coletiva, mais se deve esperar, aliás, ver os detalhes biográficos, as características físicas ganhar importância." (p. 81-82) Questão essa que se faz pertinente para o estudo de Otávio Augusto.

${ }^{7}$ Sobre o tema, recomendamos as obras de Catherine Steel, The End of the Roman Republic - 146 to 44 BC. Conquest and Crisis (2013); Kurt A. Raaflaub, Mark Toher, G. W. Bowersock, Between Republic and Empire: Interpretations of Augustus and His Principate (1993); P.A. Brunt, The Fall of The Roman Republic and Related Essays (1988) e Social Conflicts in the Roman Republic (1971); T.P. Wiseman, Roman Republic - Political Life. 90 BC-AD 69 (1985); Mary Beard e Michael Crawford, Rome in the Late Republic: Problems and Interpretations (1985).
} 
Mare Nostrum, ano 2021, v. 12, n. 1 .

desígnio dos deuses. Suetônio ressalta que havia discursos míticos em Roma que atribuíram ao princeps uma linhagem olímpica:

Segundo Júlio Márato, poucos meses antes de seu nascimento deu-se às claras um prodígio em Roma, pelo qual se inferia que a natureza estava prestes a dar à luz o rei do povo romano. [...] O Senado, atemorizado, determinou que nenhum menino nascido naquele ano fosse criado; os que tinham esposas grávidas, pois todos o esperavam para si, cuidaram para que esse decreto senatorial não fosse apresentado ao templo de Saturno ${ }^{8}$ (Aug. 94).

Cotejando esse relato com uma passagem do tratado Da República, de Cícero, percebemos sérias críticas ao sistema de governo monárquico. Segundo Marco Antônio C. Collares (2013), o tratado ciceroniano expressa a necessidade de se produzir:

[...] exemplos de harmonia e ordem em meio aos conflitos sócio-políticos de seus respectivos contextos. Com isso, vinculam-se a defesa de um ideal de concórdia enquanto valor a ser constantemente alcançado pelos romanos frente aos riscos de desagregação da República.

Portanto, a concórdia do sistema republicano deveria ser promovida como um mecanismo de segurança para a libertas dos cidadãos. Vemos em Cícero o temor de uma possível ruptura da concórdia ao afirmar que, numa monarquia, os cidadãos se encontram à margem das tomadas de decisões sobre os interesses públicos (De Rep. 1.42-43). Desde o final da monarquia etrusca, os romanos nutriam acentuada repulsa ao regime monárquico, pois o consideravam um modelo despótico e arbitrário nas coisas públicas, em que os cidadãos se encontrariam submetidos aos arbítrios e desejos de um único homem. Logo, a concórdia deveria ser a principal meta para a República, pois era o elemento que mantinha:

A unidade de todos, da plebe, tribunos e senadores é possível e a sua ausência acarreta perigos à República. Pois bem, percebe-se que esta concordia não existe

\footnotetext{
${ }^{8}$ As evidências arqueológicas apontam que o templo de Saturno teria sido construído em Roma entre 501 e 493 AEC. Ele ocupava uma área importante do forum e tinha nítida associação com a história da República (Orlin, 2002, p. 22;199; Stamper, 2005, p. 36-37).
} 
no momento e sabemos que seu restabelecimento traria mais sabedoria e felicidade para todos, assegurando a paz, o bem comum e a estabilidade. (Cícero, De Rep. 1.19)

Desse modo, ao cotejarmos o discurso mítico de Suetônio acerca do nascimento de Augusto com as palavras de Cícero, percebemos um recorrente embate do Senado contra a possibilidade de emergência de um futuro governante, o qual viesse a romper com as tradições políticas republicanas. Prosseguindo em nossa análise sobre a obra de Suetônio, verificamos que "nos livros sobre as Coisas divinas, de Asclepíades de Mendes, refere-se que Átia, tendo-se dirigido no meio da noite ao templo consagrado a Apolo e feito baixar sua liteira, cochilara enquanto as outras matronas dormiam." (Aug. 94) De imediato, o discurso elaborado pelo biógrafo se torna instigante no que se refere às questões religiosas. Afinal, ele nos possibilita compreender o templo como um local de refúgio e, consequentemente, de proteção para os cidadãos, tanto que teria sido nesse espaço sagrado dedicado a Apolo que as matronas da cidade de Velitras se refugiaram durante a gestação dos seus filhos, já que nos templos não poderia haver a profanação e o derramamento de sangue (Bustamante, 2012, p. 210). Tais atos eram passíveis até mesmo de acusação pelo crime de impiedade, sendo considerados uma ameaça à pax deorum.

Outro elemento que nos chama a atenção em Suetônio é o ato de fecundação de Augusto: “[...] de repente, uma serpente arrastou-se sorrateiramente para junto de Átia, tendo-se afastado pouco depois, e ela despertou e se purificou como se tivesse tido contato com o marido." (Aug. 94) Vemos nesse excerto uma menção direta ao momento de concepção de Augusto por Átia e Apolo. Segundo Cláudio Eliano, as serpentes têm uma longa historicidade no âmbito religioso de Roma. Afinal, elas já integravam os cultos religiosos desde a fundação da cidade de Lavínio por Eneias (História dos Animais, 11.16). Eliano também argumenta que a serpente é um animal dedicado a Apolo o qual, para além dos presságios sobre o futuro, também representava a cura de enfermidades por essa divindade (História dos Animais, 11.2).

Tal vinculação entre o réptil e o deus possivelmente reside nos discursos míticos sobre a fundação do oráculo de Delfos, bem como sobre a narrativa do seu próprio nascimento, na qual vemos sua mãe, Leto, perseguida por monstros (dentre os quais havia uma serpente) a mando da deusa Hera (Hinos Homéricos Apolo, 3. v. 300-370). Logo, cotejando os escritos de Cláudio Eliano, os Hinos Homéricos a Apolo e o discurso mítico 
forjado por Suetônio, concluímos que a serpente foi um recurso linguístico utilizado para explicar a cópula de Átia com o "deus arqueiro". Vale ainda ressaltar que Suetônio busca dar "ares" de uma relação legítima entre os amantes quando menciona que, logo após o ato, Átia fez os ritos de purificação, como se tivesse contraído intimidades com seu próprio marido (Caio Otávio).

Suetônio prossegue dizendo que, após o ato da concepção, um sinal se fez presente no corpo de Átia, o que pode denotar a marca da consumação e proteção do futuro governante romano: "Imediatamente, fez no corpo dela um sinal semelhante a uma serpente pintada que jamais pôde ser apagado, de modo que, daí em diante e para sempre, haveria de abster-se dos banhos públicos" (Aug. 94). Provavelmente, o resguardo dos banhos está ligado ao sigilo quanto à paternidade divina do futuro Caio Otávio Turino. Em decorrência dos cuidados da gens Otávia, Suetônio descreve que: “[...] tendo Augusto nascido nove meses depois, foi, por isso, considerado filho de Apolo." (Aug. 94) O relato evidencia claramente a intenção de Suetônio em associar Apolo a Augusto, desde o momento do seu nascimento, em 63 AEC. O biógrafo ainda acrescenta que:

A mesma Átia, antes de dar à luz, sonhou que suas entranhas tinham sido levantadas até os astros e espalhadas por todo o âmbito das terras e do céu. Otávio [pai] sonhou ainda que o fulgor do sol saíra do útero de Átia. (Aug. 94)

Nesse trecho, interpretamos que o parto de Augusto está repleto de acontecimentos extraordinários (prodígios), o que diviniza o seu nascimento. Mas por que Apolo? Fritz Graf (2009, p. 104) adverte que devemos expandir nossas perspectivas sobre as matrizes culturais de Apolo, pois ele era o resultado de múltiplas interações culturais, um fator que inviabiliza limitarmos esse deus em apenas uma região, nesse caso a Hélade. Luis Filipe Bantim de Assumpção (2014, p. 155) destaca que esse multiculturalismo vinculado a Apolo se confirma à medida que o seu culto se estendeu pelas sociedades mediterrâneas como um todo. Sendo assim, Apolo deve ser entendido como uma divindade mediterrânea, tanto pela importância que seu oráculo desempenhava no imaginário social da Antiguidade quanto por sua função de legitimar linhagens de governantes, ratificando assim as prerrogativas político-religiosas dos mandatários de Esparta, Atenas e na própria Roma (Assumpção, 2014, p. 155). Portanto, Apolo (divindade que zelava pela ordem), via o discurso mítico de Suetônio, daria legitimidade 
à função de Augusto como optimus princeps, o verdadeiro guardião e protetor dos cidadãos romanos.

Todavia, o relato de Suetônio corrobora nossas análises sobre como essas atividades religiosas interagiam e envolviam as esferas política e religiosa. Para David Knoke (1990, p. 7), todo papel social somente existe em relação a uma ou mais funções complementares, com as quais interage regularmente. Em outras palavras, para todo e qualquer par relacional, as regras ou normas de comportamento costumam especificar como os atores sociais podem se complementar no ordenamento social. A autoridade $\left(\right.$ auctoritas $\left.^{9}\right)$ religiosa dos atores sociais não se limitava, portanto, a uma única instituição da sociedade romana, pois suas medidas atravessavam várias camadas sociais.

Portanto, a administração das práticas religiosas romanas consideradas oficiais estava frequentemente nas mãos dos grupos dirigentes ligados ao governo da Vrbs ou das províncias, principalmente nas áreas do Mediterrâneo Ocidental. Apesar de haver uma distinção no campo historiográfico a partir das funções que cabiam à magistratura e aos colégios sacerdotais, foi possível perceber que ambos pareciam interagir recorrentemente no cenário político-religioso romano visando à manutenção do ordenamento social. Desse modo, tanto os magistrados - como os cônsules em Roma e os duúnviros ou pretores provinciais - quanto os senadores detinham, entre suas competências, o dever de manter a esfera religiosa sob seus cuidados, consultando ou interpretando os desígnios dos deuses (os auspícios) para as suas tomadas de decisão, realizando sacrifícios durante as solenidades públicas e expiando os prodígios.

Por outro lado, os magistrados não tinham a auctoritas religiosa do Senado nem o seu status permanente, pois ocupavam o cargo apenas por um breve período. Sendo assim, tanto senadores quanto sacerdotes, sobretudo os áugures, cumpriam em grande parte essa função de observação e supervisão dos sinais divinos e prodígios, a qual será manipulada, no futuro, por Augusto e seus apoiadores, a ponto de tais esferas religiosas se configurarem como elementos de ratificação do poder augustano junto à população romana.

Recebido: 01/09/2020

Aprovado: $21 / 09 / 2020$

\footnotetext{
${ }^{9}$ A auctoritas pode ser compreendida como a capacidade de alguém em exercer poder sobre a sociedade romana por meio do status que ocupava socialmente, sem o uso da força ou violência física como condicionante, em razão da reputação pessoal (Campos, 2017, p. 381).
} 
Mare Nostrum, ano 2021, v. 12, n. 1 .

\section{REFERÊNCIAS BIBLIOGRÁFICAS}

Fontes

Cassius Dio (1914-1927). Roman History. 9 vols. Loeb Classical Library. Trans.: Earnest Car. Cambridge, MA: Harvard University Press.

Cesar Augusto (2007). Res Gestae (Coisas Feitas). Tradução: Matheus Trevizam, Paulo Sérgio Vasconcellos, Antônio Martinez Rezende. Belo Horizonte - Mg: Ed. UFMG.

Cesar Augusto (2007). Res Gestae Divi Augusti. Trad.: John Scheid. Paris: Belle Lettres.

Cicerón (1869). De Legibus - Traite les lois. Paris: Imprimerie de l'Institut de France. http://remacle.org/bloodwolf/philosophes/Ciceron/lois3.htm

Cicerón (1913). De Officiis. Trad: Walter Miller. Cambridge - Mass.: Harvard University Press.

Cicerón (1921).La République. Tome I : Livre I.Texte établi et traduit par : Esther Bréguet. Paris: Belle Lettres.

Cicerón (1966). De haruspicum responso. Discours. Trad.: P. Wuilleumier; Anne-Marie Tupet. Tome XIII, 2. Paris: Les Belles Lettres.

Claudio Eliano (1984). Historia de los animales: Libros IX-XVI. Trad.: José María D. Lopez. Madrid: Editorial Gredos.

Hinos Homéricos (2010). Trad.(et. al.): Wilson Alves Ribeiro Junior. São Paulo: Ed. UNESP, 2010.

Suetônio (2007). Vida do Divino Augusto. Tradução: Matheus Trevizam, Paulo Sérgio Vasconcellos, Antônio Martinez Rezende. Belo Horizonte: Ed. UFMG.

Tite-Live (1947-1998). Histoire Romaine. Tome:I. Texte établi par: Jean Bayet. Trad: Gaston Baillet. Paris: Les Belles Lettres.

Valerio Maximo (2014). Facta et dicta memoriabilia: hechos y dichos memorables. Comentado por Alicia Schniebs, Elisabeth Caballero de del Sastre, Eleonora Tola, Roxana Nenadic, Martín Pozzi, Jimena Palacios, Viviana Diez, Gustavo Daujotas, Sara Paulin, Marcela Nasta, Florencia Cattán, Maricel Radiminski. Ciudad Autónoma de Buenos Aires: Editorial de la Facultad de Filosofía y Letras Universidad de Buenos Aires.

Obras 
Assumpção, L. F. B. Discurso e Representação sobre as práticas rituais dos esparciatas e dos seus basileus na Lacedemônia, do século $V$ a.C.. Dissertação apresentada, como requisito para a obtenção do título de Mestre, ao Programa de Pós-Graduação em História, da Universidade do Estado do Rio de Janeiro, Rio de Janeiro, 2014.

Baczko, B. (1985). A Imaginação Social. In Leach, Edmund (et Alli). Anthropos-Homem. Lisboa: Imprensa Nacional/Casa da Moeda.

Beard, M., \& Crawford, M. (1990). Pagan Priests: Religion and Power in the Ancient World. Londres: Duckworth.

Beard, M., \& Crawford, M. (1985). Rome in the Late Republic: Problems and Interpretations. Londres: Duckworth.

Bendlin, A. (1997). Peripheral centres - central peripheries: Religious communications in the Roman empire. In Cancik, H, \& Rüpke, J. (Orgs.). Römische Reichsreligion and Provinzialreligion. Tübingen, BW: Mohr Siebeck.

Bochinger, C., \& Rupke, J. (2016). Introduction. In Bochinger, Christoph, \& Rupke, Jörg (Orgs.). Dynamics of religion: Past and Present. Religionsgeschichtliche Versuche und Vorarbeiten 67. Berlin: De Gruyter.

Bustamante, R. M. C. (2006). Práticas Culturais no Império Romano: Entre Unidade e a Diversidade. In Silva, Gilvan Ventura da, \& Mendes, Norma Musco (Orgs.). Repensando o Império Romano: Perspectiva Socioeconômica, Política e Cultural (pp. 109-136). Rio de Janeiro: Mauad; Vitória: EDUFES.

Campos, C. E. C. Otávio Augusto e as suas redes político-religiosas nos quattuor amplissima collegia sacerdotum romanorum (29 AEC - 14 EC). Tese de Doutorado apresentada ao Programa de Pós-Graduação em História, da Universidade do Estado do Rio de Janeiro, Rio de Janeiro, 2017.

Collares, M. A. (2013). As representações da sociedade romana em Cícero e Tito Lívio. Revista história e-história. Acessado em 27/10/2015 e disponível em: http://www.historiaehistoria.com.br/materia.cfm?tb=professores\&id=158

Collares, M. A. Representações do senado romano na Ab Vrb Condita Libri de Tito Lívio: livros 21 - 30. Dissertação de Mestrado em História apresentada na Faculdade de História, Direito e Serviço Social - UNESP. Franca, 2009.

Girardet, R. (1987). Mitos e mitologias políticas. São Paulo: Companhia das Letras.

Gradel, I. (2002). Emperor Worship and Roman Religion. Oxford: Clarendon Press.

Graf, F. (2009). Apollo. Londres; Nova York: Routledge.

Grimal, P. (2008) O século de Augusto. Lisboa: Edições 70.

Knoke, D. (1990). Political Networks: The Structural Perspective. Cambridge: Cambridge University Press. 
MacBain, B. (1982). Prodigy and expiation: a study in religion and politics in Republican Rome. Revue d'études latines, p.7-8.

North, J. A. (2000). Roman Religion. Oxford: Oxford University Press.

Orlin, E. (2002). Temples, religion, and politics in the Roman Republic. Boston, MA: Brill Academic Publischers.

Rosa, C. B. De haruspicum responso: religião e política em Cícero. Revista Mirabilia, no3, 2003.

Rosa, C. B. (2010). Interações religiosas no Mediterrâneo romano: Práticas de acclamatio e de interpretatio. In Candido, Maria Regina (Org.). Memórias do Mediterrâneo Antigo (pp. 42-60). Rio de Janeiro: NEA/UERJ.

Rosa, C. B. (2006). A Religião da Urbs. In Silva, Gilvan Ventura da; \& Mendes, Norma Musco (Orgs.). Repensando o Império Romano: perspectiva socieconômica, política e cultural (pp. 137-159). Rio de Janeiro: Mauad, Vitória: EDUFES.

Rosa, C. B. (2015). Religião e poder: Augusto e o pontifex maximvs (36-12 aec). In Silva, Gilvan Ventura da; \& Silva, Érica Cristhyane Morais (Orgs.). Fronteiras e identidades no Império Romano: Aspectos sociopolíticos e religiosos (pp. 15-34). Vitória: GM Editora.

Rupke, J. (2001). Die Religion der Römer: Eine Einführung. Munique, BY: Verlag C. H. Beck.

Rupke, J. (2008). Fasti sacerdotum: A Prosopography of Pagan, Jewish, and Christian Religious Officials in the City of Rome, 300 BC to AD 499. Oxford; Nova York: Oxford University Press.

Rupke, J. (2015). Religious agency, identity, and communication: reflections on history and theory of religion. Religion, 45, p. 344-366.

Santangelo, F. (2013). Divination, Prediction and the end of the Roman Republic. Cambridge: Cambridge University Press.

Santangelo, F. (2016). Lei e adivinhação na República romana tardia. Hélade, v. 2, n. 2, p. 9-24.

Santangelo, F. (2011). Pax deorum and pontiffs. In Santangelo, Federico; \& Richardson, James H. (Orgs.). Priests and State in the Roman World (pp. 161-186). Stuttgart, BW: Franz Steiner Verlag.

Saraiva, F. R. S. (1993). Novíssimo dicionário Latino-Português. Etimológico, prosódico, histórico, geográfico, mitológico, biográfico e etc. Rio de Janeiro: Livraria Garnier.

Scheid, J. (2007). Augustus and Roman Religion: Continuity, Conservatism, and Innovation. In Galinsky, Karl (Org.). The Cambridge Companion to The Age of Augustus (pp. 175-194). Cambridge: Cambridge University Press. 
Carlos Eduardo Campos. Sinais Divinos e Prodígios...

Scheid, J. (1981). Le délit religieux dan la Rome tardo-républicaine. In Le délite religeux dans la cité antique (Table Ronde - Rome, 6-7 avril, 1978). Coll de l'École Française de Rome. Paris: Palais Farnese.

Stamper, J. (2005). The Architecture of Roman Temples: The Republic to the Middle Empire. Cambridge: Cambridge University Press. 
Mare Nostrum, ano 2021, v. 12, n. 1.

\section{Divine SignS AND Prodigia \\ IN THE CONSTRuCtion OF AUguStus' IMAge: \\ A STUdY From SuETonius}

\section{ABSTRACT}

The socio-political role of religion and rituals are crucial elements in the study of Roman institutions. After all, the religious sphere is part of a complex epistemological system produced by the Roman elite and related to the different social segments of Rome. Thus, from Suetonius' speeches we will analyze the construction of Augustus' legitimacy through divine signs and prodigia.

\section{KEYWORDS}

Prodigia, Senate, Suetonius, Augustus. 